\title{
Management of Hemodialysis Unit for Care Receivers in a Specialized Hospital
}

\author{
Arifa Sultana ${ }^{1}$, ANM Shamsul Islam² ${ }^{2}$ China Rani Mittra ${ }^{3}$, Salma Khatun ${ }^{4}$, Ashees Kumar Saha ${ }^{5}$
}

${ }^{1}$ Senior Staff Nurse, National Institute of Cardiovascular Diseases, Dhaka, Bangladesh; ${ }^{2}$ Associate Professor (Program Coordinator), National Institute of Preventive and Social Medicine, Dhaka, Bangladesh; ${ }^{3}$ Senior Staff Nurse, Upazilla Health Complex, Abhaynagar, Jashore, Bangladesh; ${ }^{4}$ Senior Staff Nurse, National Institute of Cardiovascular Diseases, Dhaka, Bangladesh; ${ }^{5}$ Nursing Officer, Upazila Health Complex, Bagha, Rajshahi, Bangladesh

[Received: 12 October 2020; Accepted: 30 November 2020; Published: 1 December 2020]

\begin{abstract}
Background: Chronic Kidney disease is becoming a global public health problem throughout the world. Objective: The aim of the study was to assess the management status of hemodialysis unit for care receivers in a specialized hospital. Methodology: This was a hospital based descriptive cross-sectional study. The participants were selected by purposive sampling method on the basis of defined selection criteria from January 2015 to December 2016. The place of study was National Institute of Kidney Diseases and Urology (NIKDU) hospital, Dhaka. The research instruments were a semi structured questionnaire and an observational checklist. Data were collected from respondents by face to face interview and an observational Checklist was also used to collect information regarding administrative facility, physical facility and utility services. Result: The findings of the study were presented by frequency, percentage in tables. Means and standard deviations for continuous variables and frequency distributions for categorical variables were used to describe the characteristics of the total sample. Among the service receiver, mean age was $46.65 \pm 13.53$ years of which $69.9 \%(n=58)$ were male and their average monthly income Tk. 20670 \pm 14811 . Formalin and hydrogen per oxide were used to wash dialyzer. In the support services unit, equipment and stationery were supplied always. Ratio of health care receiver and provider in the unit was Patient-doctor ratio 1:15 and Patient-nurse ratio 1:6. From the respondents 38 $(45.8 \%)$ said that, doctor/ nurse visit them thrice per cycle. In majority of respondents, were satisfied regarding the unit including doctors and nurses activities, physical facilities, and cleanliness of the unit, except the cleanliness of toilet. Conclusion: Increasing number of functioning dialysis machine, skilled manpower, medicine supply and strict infection control measure could be helpful to improve the management status of the hemodialysis unit of NIKDU. [Bangladesh Journal of Infectious Diseases, December 2020;7(2):84-89]
\end{abstract}

Keyword: Dialysis; hemodialysis; chronic kidney disease; end-stage renal disease; reuse of dialyzers; service facilities

Correspondence: Arifa Sultana, Senior Staff Nurse, National Institute of Cardio Vascular Diseases, Sher-E-Bangla Nagar, Dhaka, Bangladesh; Cell no.: +8801728877088; Email: arifasultana915@gmail.com

Conflict of interest: None declared

Funding agency: None of the authors have received any funding from any person or any organization.

Contribution to authors: Haq NU, Nasim A involved in protocol preparation, data collection and literature search up to manuscript writing. Kakar P involved in literature search, preparation and revision of this manuscript.

How to cite this article: Sultana A, Islam ANMS, Mittra CR, Khatun S, Saha AK. Management of Hemodialysis Unit for Care Receivers in a Specialized Hospital. Bangladesh J Infect Dis 2020;7(2):84-89

Copyright: (2020. Sultana et al. Published by Bangladesh Journal of Infectious Diseases. This article is published under the Creative Commons CC BY-NC License (https://creativecommons.org/licenses/by-nc/4.0/). This license permits use, distribution and reproduction in any medium, provided the original work is properly cited, and is not used for commercial purposes. 


\section{Introduction}

The burden of Chronic Kidney Disease (CKD) is increasing in alarming proportion all over the world. In Bangladesh due to lack of financial resources, lack of trained manpower \& infrastructure leads to severe strain on existing health policies in the light of the increasing burden of CKD. Kidneys are probably the only vital organs which can be realistically replaced by artificial means. Maintenance dialysis is a well-recognized modality of treating patients having end stage renal disease. Several thousands of patients all over the world are surviving and achieving reasonable quality of life on maintenance dialysis. The exact burden of CKD needing maintenance dialysis and/ or renal transplantation is not known; however, from the existing published data prevalence of CKD ranges between $0.7 \%$ to $1.4 \%$ cases. Whereas the incidence of end stage renal disease was estimated to be 180 to 200 per million populations ${ }^{1}$.

Diabetes is the main cause of kidney failure in most countries, accounting for $40 \%$ or more of new patients $^{2}$. Prevalence of CKD seems to be increasing particularly in older individuals ${ }^{3}$. Hemodialysis is the mainstay therapy which is offered for ESRD patients who cannot undergo renal transplantation. Situation of Bangladesh is not different. A central issue in the management of patients undergoing maintenance hemodialysis (HD) is the assessment of the adequacy of dialysis ${ }^{4}$. Despite its dramatic success at saving lives, HD remains far from perfect therapy. More than 20.0\% cases of hemodialysis patients die each year ${ }^{5}$. In developed countries usually hemodialysis is done thrice a week. However in India only $20.0 \%$ cases of patients are dialyzed 3 times a week ${ }^{6}$. Although it is well-known that increasing the frequency of dialysis improves the quality of life but it is a difficult option due to pressure from too many patients and inadequate hemodialysis machines.

About $85.0 \%$ cases of the world populations live in less developed part of the world where CKD prevention programs are either rudimentary or virtually non-existent ${ }^{7}$. Morbidities and mortalities emanating from CKD in these countries are immense and related to limited access for treatment options $^{8}$. Renal replacement therapy (RRT) is the mainstay of care for patients with end stage renal disease (ESRD). Dialysis as an option of RRT prolongs survival, reduces morbidities and improves quality of life. However, despite many technical advances, morbidities and mortalities of patients on dialysis remain unacceptably high and their quality of life is often poor ${ }^{9}$. Common independent predictors of survival are age, race, serum albumin at the start of dialysis, activity level at the start of dialysis, and presence of certain comorbidities such as heart failure and cancer ${ }^{10}$.

World over there is severe shortage of donor kidneys. In our country deceased donor transplantation Programme is as yet in its infancy and because of breaking up of joint family structure the live donor programme is not enough for the needs of ESRD patients. Therefore several thousands of patients have to live on maintenance dialysis in Bangladesh. Maintenance dialysis importantly serves as a bridge to kidney transplantation. Our descriptive cross sectional study was aim to assess the management status of hemodialysis unit for care receivers in a specialized hospital.

\section{Methodology}

The study was a descriptive type of cross-sectional study. The study was carried in hemodialysis unit of National Institute of Kidney Disease and Urology (NIKDU), Dhaka. The total study period was January 2016 to December 2016 for a period of one year. Study Population was Health care receivers of hemodialysis unit. Purposive sampling technique was done. Semi-structured interviewer administered questionnaire was developed to collect the data. The questionnaire was prepared by using the selected variables according to objectives. A Semistructured interviewer administered questionnaire was developed to collect the data. The questionnaire was prepared by using the selected variables according to objectives. Data were collected from respondents by face to face interview and an observational. The questionnaire was pretested in Dhaka. Necessary modifications were done and finalized before collection of data. For collection of data, both questionnaire and checklist were used. First part of the questionnaire included personal information of the respondents. Second part of the questionnaire contained questions to assess the clinical and nursing services, support services. Checklist was used to collect information regarding administrative facility, physical facility and utility services. The investigator himself collected data from the selected hospitals. Data were collected by face to face interview. Check list was filled up after observing the unit all through the data collection period. This study was conducted with the intention of protecting the human rights of all subjects. All the information collected for the study was utilized only for the purpose of thesis and was not disclosed to anyone outside the research team. At the beginning, approval was obtained from the ethical 
committee of NIPSOM, under the Bangabandhu Sheikh Mujib Medical University, Dhaka, Bangladesh. Before collection of data, written permission was taken from the director of the corresponding hospital and also informed written consent was obtained from participants after informing about the purpose of the study. A complete assurance was given that all information keeps confidentially. Inclusion criteria include willing to participate in the study and taking treatment facility for at least one week. Exclusion criteria include mentally retarded patients and severely ill patients.

\section{Result}

After completion of the data analysis, the results were organized in the tabular form as necessary respectively.

Table 1: Socio-Demographic Status of the Health

\begin{tabular}{|l|c|c|}
\hline Variables & Frequency & Percent \\
\hline Age Group & 20 & 24.1 \\
\hline Up to 30 years & 8 & 9.6 \\
\hline $31-40$ years & 20 & 24.1 \\
\hline 41-50 years & 35 & 42.2 \\
\hline Above 50 years & 58 & 69.9 \\
\hline Gender \\
\hline Male & 30.1 \\
\hline Female & 25 & 8.4 \\
\hline Educational Qualification & 7 & 26.5 \\
\hline Illiterate & 50.6 \\
\hline Primary passed & 22 & 9.6 \\
\hline SSC passed & 42 & 4.9 \\
\hline HSC passed & 8 & 73.5 \\
\hline Above HSC & 4 & 8.4 \\
\hline Occupation & \multicolumn{2}{|l|}{} \\
\hline $\begin{array}{l}\text { Not involved in any } \\
\text { job }\end{array}$ & 61 & 10.8 \\
\hline Service holder & 7 & 7.2 \\
\hline Business & 9 & 45.7 \\
\hline Others & 6 & 37.3 \\
\hline Monthly Family Income (in taka) \\
\hline Up to 15000 taka & 38 & 9.3 \\
\hline 16000-30000 taka & 31 & 6 \\
\hline 31000-45000 taka & 6 & \\
\hline Up to 15000 taka & 8 \\
\hline
\end{tabular}

The mean age of the health care receiver was $46.65 \pm 13.53$ years. Among them 42.2\% respondents were from above 50 years age group. Among the respondents $69.9 \%$ respondents were male and $30.1 \%$ were female. Educational Care Receivers $(\mathbf{n}=\mathbf{8 3})$

qualification shows that among the respondents $26.5 \%$ were primary passed, 50.6\% were SSC passed, 9.6\% were HSC passed and $4.9 \%$ were above HSC. Occupation shows that $73.5 \%$ respondents were not involved in any job, $8.4 \%$ were service holder, $10.8 \%$ were business and others occupation were $7.2 \%$. The mean monthly income of the health care providers was $20670.34 \pm 14811.53$ taka. Among them 45.7\% respondents had monthly income up to 15000 taka (Table 1).

Table 2: Vascular Access and Reuse Dialyzer Facility of the Unit

\begin{tabular}{|l|c|}
\hline Vascular access & Criteria \\
\hline Vascular access facility & Available \\
\hline Type of vascular access & $\begin{array}{c}\text { Femoral catheter and } \\
\text { jugular catheter }\end{array}$ \\
\hline $\begin{array}{l}\text { Personnel involved in } \\
\text { performing vascular } \\
\text { access }\end{array}$ & Doctor \\
\hline $\begin{array}{l}\text { Personnel involved in } \\
\text { taking care of vascular } \\
\text { access }\end{array}$ & Criteria \\
\hline Dialyzer & Available \\
\hline Facility to reuse dialyzer & $\begin{array}{c}\text { Formalin and } \\
\text { hydrogen per oxide }\end{array}$ \\
\hline $\begin{array}{l}\text { Materials used to wash } \\
\text { dialyzer }\end{array}$
\end{tabular}

The vascular access facility was present. In the unit, done only femoral catheter and jugular catheter or access. Doctor performed the vascular access procedure and nurse took care of the access and dialyzer reuse facility was also present. Formalin and hydrogen per oxide were used to wash dialyzer (Table 2).

Table 3: Utility and Support Services of the Unit

\begin{tabular}{|l|c|}
\hline Utility services & Criteria \\
\hline Linen is changed for every patient & Not always \\
\hline Dietary service for patients & Absent \\
\hline $\begin{array}{l}\text { All accumulated waste materials } \\
\text { are removed }\end{array}$ & Daily \\
\hline Frequency of cleaning the unit & Daily \\
\hline Twenty four hour security services & Absent \\
\hline Support services & Criteria \\
\hline $\begin{array}{l}\text { All the necessary equipment's are } \\
\text { supplied to patients from the } \\
\text { hospital }\end{array}$ & Always \\
\hline $\begin{array}{l}\text { All the necessary medicines are } \\
\text { supplied to patients from the } \\
\text { hospital }\end{array}$ & Sometimes \\
\hline $\begin{array}{l}\text { Necessary investigation facilities } \\
\text { are available in the hospital }\end{array}$ & Sometimes \\
\hline
\end{tabular}




\begin{tabular}{|l|l|}
\hline $\begin{array}{l}\text { All the necessary stationeries are } \\
\text { supplied from the hospital to the } \\
\text { unit }\end{array}$ & Always \\
\hline
\end{tabular}

In the unit, linen was not always changed for every patient. Dietary service for patients were absent, all accumulated waste materials were removed daily and frequency of cleaning the unit were done daily and twenty four hour security services were absent. In the support services unit, equipment and stationery were supplied always. But medicine and investigation facility were Sometimes (Table 3 ).

Table 4: Distribution of Personnel and Ratio of Health Care Receiver and Provider in the Unit

\begin{tabular}{|l|c|}
\hline Personnel & Number \\
\hline Physician for dialysis patient & 4 \\
\hline Nurse & 15 \\
\hline Technician & 5 \\
\hline Word boy & 4 \\
\hline Total & 28 \\
\hline Patient : Health care provider & Criteria \\
\hline Patient-doctor ratio & $1: 15$ \\
\hline Patient-nurse ratio & $1: 6$ \\
\hline
\end{tabular}

The total number of personnel in hemodialysis unit was recorded. In hemodialysis unit, there are 28 personnel in total. Among them, no. of physician for dialysis patient is 4 and no. of nurses for dialysis patient is 15 , no of technician were 5 and word boy 4. Ratio of health care receiver and provider in the unit was Patient-doctor ratio 1:15 and Patient-nurse ratio 1:6 (Table 4).

Table 5: Clinical and Nursing Service Related Information of the Health Care Receiver $(n=83)$

\begin{tabular}{|l|c|c|}
\hline $\begin{array}{l}\text { Clinical and nursing } \\
\text { service }\end{array}$ & Frequency & Percent \\
\hline No. of time doctor/ nurse visit the patient \\
\hline 2 times & 11 & 13.3 \\
\hline 3 times & 38 & 45.8 \\
\hline More than 3 times & 34 & 40.9 \\
\hline
\end{tabular}

The distribution of clinical and nursing service related information of the health care receiver was recorded. According to 38(45.8\%) respondents, doctor/ nurse visit them thrice per cycle, among them 34 (40.9\%) respondents, doctor/ nurse visit more than 3 times per cycle, and 11(13\%) respondents, doctor/ nurse visit 2 times per cycle (Table 5).
Table 6: Patient's Satisfaction Regarding the Unit (n=83)

\begin{tabular}{|l|c|c|}
\hline $\begin{array}{l}\text { Patient's Satisfaction } \\
\text { Regarding The Unit }\end{array}$ & Frequency & Percent \\
\hline Satisfied with Doctor's Activity \\
\hline Satisfied & 61 & 73.5 \\
\hline Not satisfied & 22 & 26.5 \\
\hline Satisfied with Nurses' Activity \\
\hline Satisfied & 59 & 71.1 \\
\hline Not satisfied & 24 & 28.9 \\
\hline Satisfied with Physical Facilities \\
\hline Satisfied & 57 & 68.7 \\
\hline Not satisfied & 26 & 31.3 \\
\hline Satisfied with Cleanliness Of The Unit \\
\hline Satisfied & 63 & 75.9 \\
\hline Not satisfied & 20 & 24.1 \\
\hline Satisfied with cleanliness of the toilet \\
\hline Satisfied & 20 & 24.1 \\
\hline Not satisfied & 63 & 75.9 \\
\hline
\end{tabular}

The patient's satisfaction regarding the unit was recorded. In majority of respondents, were satisfied regarding the unit including doctors and nurses activities, physical facilities, and cleanliness of the unit, except the cleanliness of toilet (Table 6).

\section{Discussion}

Dialysis is the treatment that artificially performs the function of the kidneys removing the wastes, salt and extra fluids from the blood. There are two different modalities of dialysis, hemodialysis and peritoneal dialysis. Hemodialysis uses a machine to accomplish the dialysis treatment, and it can be performed in hospitals, special dialysis centers, doctors have to create an access or entrance into the blood vessels of the patient in order to be able to connect the patient to the dialysis machine and a special filter called dialyzer or artificial kidney.

The utility service of the unit was observed. It was found that, in the unit, linen was not always changed for every patient. All accumulated waste materials were removed daily. Twenty four hour security services were absent. There were three shifts in the unit. As more patients came in morning shift, more health care provider worked in morning shift. But in night shift, less number of health care provider worked as less patients came at night shift. On an average, the nurse patient ratio was 6:1 and the doctor patient ratio was 16:1. Chronic hemodialysis patients are at high risk for infection because the process of hemodialysis requires vascular access for prolonged periods. In an environment where multiple patients receive 
dialysis concurrently, repeated opportunities exist for person to person transmission of infectious agents, directly or indirectly via contaminated devices, equipment and supplies, environmental surfaces, or hand of personnel. Furthermore, hemodialysis patients are immunosuppressed which increases their susceptibility to infection, and they require frequent hospitalization and surgery, which increase their opportunities for exposure to nosocomial infections ${ }^{11}$.

In the unit, vascular access facility was present. Doctor performed the vascular access procedure and nurse took care of the access. During dialysis, the patient, the dialyzers and the dialysate both required constant monitoring because numerous complications are possible, including clotting of the circuit, air embolism, inadequate or excessive ultrafiltration (hypotension, cramping and vomiting),blood leaks, contamination and access complications. The nurses in the dialysis unit have an important role in monitoring, supporting, assessing and education the patient ${ }^{12}$.

In the hemodialysis unit of NIKDU, dialyzer reuse facility was present. Formalin and hydrogen per oxide were used to wash dialyzer. According to the respondent's statement, $45.8 \%$ respondents said that doctor/ nurse visit them at least three times. $40.9 \%$ respondents said that doctor/ nurse visit them more than three times. Majority of the health care provider $(76.5 \%, \mathrm{n}=13)$ were unsatisfied with the services of the CSSD department of the unit. The socio-demographic status of the health care receiver was also revealed in the current study. It was found that the mean age of the health care providers was $46.65 \pm 13.53$ years. Among them $42.2 \%$ respondents were from above 50 years age group. Among the respondents $69.9 \%$ respondents were male.

A study conducted at Nephrology unit of Dhaka Medical College Hospital (DMCH) to see the association between epidemiological pattern of renal insufficiency with socio demographic factors, kidney related factors and others factors where they found patients suffering from CKD with male and female ratio being 1.5:1, mean age of the population was 47 years $(\mathrm{SD} \pm 14.5)^{13}$. In this study revealed that most of the respondents $(90.3 \%, n=75)$ did dialysis twice per week. Majority of the respondents $(61.4 \%, \mathrm{n}=51)$ did dialysis for 1 to 2 years. A study found mean time on dialysis was 2 to 11 year $^{14}$. The dissimilarity of the result might be due to the fact that (Suri et al) had done a meta-analysis where they include the patients of developed country where the survival rate of $\mathrm{CKD}$ is more than developing country.

In the present study patient's satisfaction regarding the unit were assessed. In majority of cases, patients were satisfied regarding the unit except the cleanliness of toilet. $75.9 \%(n=63)$ respondents were dissatisfied with the cleaning status of the unit.

\section{Conclusion}

CKD is becoming a major public health problem worldwide. Hemodialysis is the ultimate treatment of CKD in developing country like Bangladesh. NIKDU is the only Institute for Nephrology and Urology in Bangladesh and provides education, research \& treatment facilities for nephrology and urological diseases. From the current study it was found that the hemodialysis unit is well located. But the functioning dialysis machine and medicine supply was inadequate to meet the huge patient load. There was no vaccination for facilities for health care provider and receivers. Increasing number of functioning dialysis machine, skilled manpower, medicine supply and strict infection control measure could be helpful to improve the management status of the hemodialysis unit of NIKDU.

Acknowledgement: I express my sincere gratitude to my respected teacher Dr. Kazi Jahangir Hossain, PhD, Associate professor, Department of Health Education, Program Coordinator, National Institute of Preventive and Social Medicine (NIPSOM), Mohakhali, Dhaka, Prof Dr. Baizid Khoorshid Riaz, Director of National Institute of Preventive \& Social Medicine (NIPSOM), Mohakhali,Dhaka for his kind suggestion and immense cooperation, Dr. ANM Shamsul Islam Associate Professor, Department of public health and Hospital Administration, Course in charge, Hospital Management for his constructive and valuable advices. My hearty thanks go to the service providers and receivers at Hemodialysis unit, National institute of Kidney Diseases and urology (NIKDU) those were participated in this study for their cooperation and contribution. Finally, I would like to thank to my beloved of son, parents and my husband for their support and patience during the completion of this research work and dissertation.

\section{References}

1. Rajapurkar M, Dabhi M. Burden of disease prevalence and incidence of renal disease in India Clinical Nephrology 2010;74-Suppl.1(S9-S12)

2. Kepler J, Annual Data Report: Atlas of Chronic Kidney Disease and End-Stage Renal Disease in the United States. 2010; Vol. 2

3. Coresh J, Selvin E, Stevens L.A, Manzi J, Kuse JW, Eggers $\mathrm{P}$, et al. Prevalence of chronic kidney disease in the United States. JAMA 2007;298:2038-47

4. Casula A, Webb L, Feest T, Adequacy of hemodialysis in UK adult patients in 2009: National and centre-specific 
analyses. UK Renal Registry 13th Annual Report 2011;119 141-7

5. USRDS (US Renal Data System), Annual Data Report: Atlas of End-Stage Renal Disease in the United States, Bethesda, National Institutes of Health, National Institute of Diabetes and Digestive and Kidney Diseases; 2016:23

6. Rao M, Juneja R, Shirly RB, Jacob CK. Haemodialysis for end-stage renal disease in Southern India-A perspective from a tertiary referral care centre. Nephrol Dial Transplant. 2016;13:2494-500

7. Grassman A, Gioberge S, Moeller S, Brown G: ESRD patients in 2004: Global overview of patient numbers, treatment modalities and associated trends. Nephrol Dial Transplant 2005;20:2587-2593

8. Fatiu A, Rashad S. CKD Prevention in Sub-Saharan Africa: A Call for Governmental, Nongovernmental, and Community Support. Am J Kidney Dis 2008, 51:515-523

9. US Renal Data System: USRDS. Annual Data Report. Bethesda: National Institutes of Health, National Institute of Diabetes and Digestive and Kidney Diseases; 2002
10. Bleyer AJ, Tell GS, Evans GW, Ettinger WH Jr, Burkart JM: Survival of patients undergoing renal replacement therapy in one center with special emphasis on racial differences. Am J Kidney Dis 1996, 28(1):72-81

11. Karkar A, Bouhaha BM, Dammang ML. Infection control in hemodialysis units: A quick access to essential elements. Saudi J Kidney Dis Transpl 2014;25:496-519

12. Bakey J. Evaluation of Nurses' Practices throughout Hemodialysis Treatment for Patients in hemodialysis unit at Baghdad teaching hospitals. Kufa Journal for Nursing Sciences, 2012;2

13. Haq MN, Rahman L, Gazi EA, Baroi SC. Epidemiological Pattern of Renal Insufficiency among the Patients of Nephrology Unit of DMCH ,Dhaka ,BD,F.M College Journal 2013;8(2):80-84

14. Suri, R., Nesrallah, G., Mainra, R., Garg, A., Lindsay, R., Greene, T. and Daugirdas, J. Daily hemodialysis: A systematic review. Clinical journal of the American Society of Nephrology: CJASN 2007;1(1):33-4 